\title{
Non-pharmacological methods of fighting dental anxiety
}

\author{
Joanna Rosiak', Jolanta Szymańska' \\ ${ }^{1}$ Department of Integrated Paediatric Dentistry, Medical University, Lublin, Poland \\ Rosiak J, Szymańska J. Non-pharmacological methods of fighting dental anxiety. J Pre-Clin Clin Res. 2018; 12(4): 145-148. doi: 10.26444/jpccr/99771
}

\begin{abstract}
Anxiety related to dental prophylactic and therapeutic procedures and experienced by children, adolescents and adults is an important obstacle in the everyday practice of dental professionals. The methods to reduce and/or eliminate dental anxiety and to influence patients' attitudes may be divided into the non-pharmacological and pharmacological. The presented study analyzes the specialist literature available through Pubmed and Google Scholar databases, examining the papers published during the 10 years prior to this study. The article, discusses non-pharmacological methods of fighting dental anxiety, including basic behavioural as well as alternative methods, such as using VR goggles, music and hypnosis. The authors also report evaluations of the effectiveness of these methods in clinical dental practice, while at the same time stressing that such an assessment is extremely difficult. Most research covers only those patients who report to dental surgeries, which results in excluding subjects who feel too great an anxiety to seek the help of a dentist. Various sources assessing the effectiveness of the various methods are cited. The popularization and more frequent use of the methods for reducing and/or elimination of dental anxiety chosen according to the patient's age, personality, temperament, and his/her anxiety level is beneficial both for the patient suffering from dental anxiety and for the dentist.
\end{abstract}

\section{Key words}

dental fear/dental anxiety (DFA), psychology, prevention and control

\section{INTRODUCTION}

The knowledge on how to deal with dental anxiety in patients is not widespread among dentists and the lack of that knowledge means discomfort at work [1]. The methods for reducing and/or eliminating dental anxiety and influencing dental patients' attitudes include both pharmacological and non-pharmacological methods [2]. Parents of children experiencing dental anxiety definitely prefer using nonpharmacological methods [3]. Effective coping with dental fear is extremely important in both adult and paediatric patients. As researchers suggest, the fact that a woman suffers from dental anxiety might be an important factor in the development of the condition in question in her child [4]. In order to overcome the phobia, a dental professional should choose a method corresponding to the anxiety level [5].

Assessing the effectiveness of every method to fight dental anxiety may be extremely challenging. Usually, only patients who have overcome their dental fear take part in studies. This means that individuals with high dental anxiety levels are excluded - since they experience too high anxiety levels to report to the dentist [6].

\section{OBJECTIVE}

The paper aims to present non-pharmacological methods for fighting dental anxiety and to evaluate their effectiveness on the basis of the research literature published during the 10 years prior to the study, and available through the Pubmed and Google Scholar databases.

Address for correspondence: Jolanta Szymańska, Department of Integrated Paediatric Dentistry, Medical University, Lublin, Poland

E-mail: szymanska.polska@gmail.com

Received: 31 October 2018; Accepted: 13 November 2018

\section{BASIC BEHAVIOURAL METHODS}

It is very important for a dental practitioner to be familiar with behavioural methods in order to influence the actions of paediatric patients. Basic behavioural methods include: verbal and non-verbal communication (Tell-Show-Do - TSD), voice control, positive reinforcement, parent's presence/absence in the practice, modelling, and systematic desensitization [7]. The use of behavioural techniques allows dealing with dentophobic patients in the correct way, yet not many dental practitioners use these techniques [8]. Kaczmarek et al. claim that most Polish dentists favour positive reinforcement, communication with the child prior to the procedure, and the Tell-Show-Do method [2]. Vishwakarma et al. compared the effectiveness of modelling and the Tell-Play-Do (TPD) method (a modification of the above-mentioned Tell- Show-Do).

According to the TPD method, the child can play with basic dental tools. Researchers have found the TPD method to be more effective in reducing dental anxiety, when compared with the modelling method. Furthermore, the paediatric patients (the examined group were individuals aged 5-7) have proven more eager to cooperate with every subsequent visit to the dentist [9]. In the case of adults, practitioners can modify the method to make it more effective and suitable for the patient's needs. It might be implemented as Explain-AskShow-Do, thanks to which the adult patient gains the sense of control over the procedure and predictability [5]. In the case of children aged $4-5$, showing cartoons on a screen is more effective than using the TSD method. This is due to the fact that cartoons are more of a visual distraction. Yet, implementing these procedures led to no improvement in children's overall behaviour, as rated using the Frankl Scale [10].

When analyzing the effectiveness of the modelling method in children, researchers should take into account the subject's personality, as well as age. This method was 
the most effective in children aged 7-9 with the mother as a model. However, in children aged 5-9, and also when fathers were models, both modelling and TSD have proved to be less effective [11].

A digital solution based on systematic desensitization called CARL (Computer-Assisted Relaxation Learning) was found to be effective in reducing dental anxiety in adults. This method lets the patient learn relaxation methods, such as proper breathing or muscle relaxation, and go through the steps of injection [12]. Parent's presence/absence during the first and second visit to the dentist had no influence on reducing dental anxiety in 5-year-olds [13]. Pani et al. have observed that children aged 6-8 undergoing dental surgeries with no parent present reported lower anxiety levels [14].

Communication. It is often assumed that in case of patients with low dental anxiety levels (with no additional problems), the relationship with the dental professional is based on trust, as well as true information regarding the methods of treatment, are sufficient for reducing anxiety symptoms. For a dental professional, the following factors are important: careful choice of words, empathic attitude toward the patient and pleasant tone of voice [5]. The ability to communicate with the dental professional during the procedure increases patients' comfort. However, communication can be challenging, particularly during procedures requiring the use of a cofferdam. Singh et al. suggested using the 'touch n'tell' system during surgeries on adult patients. They created a system based on two screens - one visible to the patient, the other for the dental professional. The patient is given a remote control and uses it to change the information displayed on the screen. Thanks to this, they can inform the dentist about the discomfort they feel. Researchers have found a significant reduction in dental anxiety levels, as measured by the MDAS (The Modified Dental Anxiety Scale) in patients who used the "touch n'tell"; system during the procedure [15].

Kazancioglu et al. have examined the anxiety levels in adult patients undergoing dental surgical procedures. In these patients, the level of dental anxiety was mostly affected by the way dental professionals provided them with information about post-procedure recovery. It was important that the information was detailed. The patients who watched a video about a dental implant surgery prior to undergoing one have reported significantly higher anxiety levels, compared to patients who have received either general or detailed oral information about the surgery. The patients' attitudes were assessed using both the MDAS and STAI (Spielberger's StateTrait Anxiety Inventory) scale. The latter (STAI) contains two parts: $\mathrm{S}$ - anxiety for assessing the current anxiety level, and $\mathrm{T}$ - anxiety for assessing the individual's vulnerability to stress. The lowest anxiety levels were reported in patients who had received detailed written information about the procedure and post-surgery recovery [16]. An increase in the levels of anxiety and pain during the surgery were observed during the surgical removal of third molars in patients who had watched a video showing the procedure [17].

It is also possible to lower dental anxiety levels by using various distracting objects. Their effectiveness was confirmed based on the observations of children aged 4-6. In the cited study, the subjects received a mirror to watch the procedure and control it [18].
Cognitive-Behavioural Therapy - CBT. The effectiveness of this therapy method has already been confirmed in psychiatry, especially when dealing with anxiety disorders and phobias [19, 20,21]. Cognitive-behavioural therapy has proved to be an effective way of reducing dental anxiety, especially in adult patients with moderate anxiety levels $[21,22]$. Furthermore, the CBT therapy is more effective in lowering dental anxiety levels than pharmacological sedation or anaesthesia [23]. Forbes et al. have shown that over a half of the patients suffering from dentophobia are likely to undergo a psychological or behavioural therapy to eliminate fear. Yet, $71 \%$ of the surveyed did not consider this therapy as effective, which means that they would not choose it [24].

It might be challenging to solve emotional issues by addressing them directly. This is where the CBT comes in handy. The method is used to influence the way patients act and approach various items and situations through biofeedback, relaxation, exposure and cognitive restructuring [14]. In most cases, cognitive-behavioural therapy is provided by psychologists. Dentists can also provide that kind of therapy - provided that they have undergone proper training [5]. Additionally, some computer-based and online solutions were introduced to provide easier access to therapy $[6,19]$.

Shahnavaz et al. have confirmed that an online cognitivebehavioral therapy is effective in reducing dental anxiety. It also encourages children and adolescents to visit a dentist. This kind of therapy is based on the same principles as the regular CBT. Yet, instead of face-to-face sessions, all the therapeutic work is done online [20]. In another study, Shahavaz et al. have observed that children undergoing the regular CBT easier cope with fear and dental procedures. Moreover, after the therapy is finished, $91 \%$ of the subjects show no dental anxiety, as rated using various diagnostic criteria, which proves that it is highly effective [25]. The effectiveness of computer-based cognitive-behavioural therapy in reducing dental anxiety (as measured with MDAS) has been confirmed for patients aged 9-16 and 18-70 [6, 26]. Another study has shown that four therapeutic sessions using cognitive restructuring are sufficient to significantly decrease dental anxiety levels in patients suffering from the condition [27].

\section{ALTERNATIVE METHODS}

It was found that distracting the attention of patients suffering from anxiety might be effective in fighting mild and moderate forms of dental anxiety [5]. Anything in the patient's surroundings may increase dental anxiety levels the very moment he enters the practice. Krisidima et al. show that this might be eliminated even by distributing scents (e.g. lavender) in the practice's waiting room, as they may reduce fears related to a dental visit [28].

Virtual reality goggles. Modern technologies are increasingly often used as ways of dealing with dental anxiety [29, 30, 31]. However, the effectiveness of this method may vary, which is related to the methodology of the examination and the type of surgery.

A FLACC scale (face, legs, activity, cry, consolability) was used to measure the patient's discomfort caused by a visit to the dentist. For this purpose, the same patients underwent 
various surgeries, both with and without wearing VR goggles. No statistically significant differences regarding stress levels were found.

The authors of this study examined patients aged 5-8, without any previous negative dental experiences [28]. A decrease in the pain felt while making a filling in milk teeth and in the anxiety related to the visit was observed in children aged 4-6. They had previously been assessed with the Modified Children Dental Anxiety Scale (MCDAS). Researchers used VR goggles to distract the patients' attention during the procedure [30].

Another researcher, Panda, has successfully managed to reduce the subjective pain sensation during dental procedures conducted in children aged 6-8, using VR goggles. However, it should be emphasized that virtual reality goggles are effective if young patients watch pictures they already know, such as cartoons. Using new, previously unknown pictures might cause discomfort and stress [32].

The use of VR goggles, however, has its limitations. Fakhruddin et al. have observed that using goggles along with behavioural methods in the treatment of children with hearing problems increases the levels of dental anxiety. Using behavioral methods and visual distractions is therefore recommended for such children. However, the operating field should remain fully visible, although in the case of patients with no hearing issues, watching pictures on a screen is less effective than using VR goggles. This may be due to the fact that children with impaired hearing have no control over their surroundings and experience anxiety whenever they are unable to maintain visual contact [33].

Music. Numerous research studies have shown that music is an effective way of overcoming dental fear $[5,34,35,36$, 37]. Music therapy is an effective way of reducing pain and anxiety in children undergoing dental or medical procedures. This has been confirmed through a meta-analysis of 19 clinical studies [37]. It is suggested that listening to music for 10 minutes is sufficient to reduce anxiety related to dental visits, and a significant reduction in dental anxiety has been reported in patients who listened to music for 10 minutes prior to the surgery, unlike patients who waited for the procedure in silence [34]. On the other hand, Mehr et al. have observed the effectiveness of music therapy in patients suffering from dental anxiety, as well as those who have undergone a particular dental procedure for the first time. Music distracted patients during a dental visit and made it more attractive [35].

It was established that audio-distraction is an effective way of reducing anxiety. Patients who were subject to it reported lower anxiety levels, when compared to those undergoing the surgery in silence. This was confirmed by a study involving children aged 6-12 and using various audio-distraction method. Audiobooks with popular children's stories were even more effective [36]. In adult patients, music therapy has also proved to be effective. This was observed during the surgery of removing third molars (wisdom tooth). Patients reported lower anxiety levels, in comparison to those who underwent the procedure in silence [38].

Lahmann et al. have proved that the relaxation and distraction methods implementing music can be effective in reducing dental anxiety. Yet, it was the relaxation techniques that proved more effective in patients with high dental anxiety levels [39].
Hypnosis. Hypnosis is considered an effective way to reduce anxiety and stress related to dental fear $[5,13,40]$. Hypnosis makes the subject focus on internal feelings, thoughts, sounds and sensations coming from his/her own body, thus eliminating the influence of external stimuli on what he/she is experiencing $[5,41]$. Hypnosis puts the subject into a state of deep relaxation, significantly reducing pain during dental procedures. It also reduces the patient's fear related to the use of a needle necessary in traditional forms of anaesthesia [42]. Sometimes, the relaxation level is so high that it is possible to perform the surgery without anaesthesia [8]. Hypnosis may also be helpful in controlling the patient's gag reflex, and may be successfully used in paediatric dentistry [24, 43]. Using hypnosis is currently recommended as an additional method to reduce anxiety in patients before dental treatment, although a survey study conducted by Panek et al. has shown that only $1 / 5$ of the respondents declared themselves willing to undergo hypnosis during dental conservative procedures [44].

\section{CONCLUSIONS}

Spreading knowledge about reducing/eliminating patients' dental anxiety with the use of behavioural and alternative methods and more frequent use of such methods may be beneficial both to patients suffering from anxiety and to dental professionals. However, the methods of fighting dental fear have to be adapted to the patient' age, personality, temperament, and anxiety level.

\section{REFERENCES}

1. Hill KB, Hainsworth JM, Burke FJT, Fairbrother KJ. Evaluation of dentists' perceived needs regarding treatment of the anxious patient. Br Dent J. 2008; E13.

2. Kaczmarek U, Grzesiak-Gasek I, Lisiecka K. Methods of child's adaptation to dental treatment used by dental practitioners - preliminary report. Czas Stomatol. 2009; 62(1): 23-33.

3. Muhammad S, Shyama M, Al-Mutawa SA. Parental attitude toward behavioral management techniques in dental practice with schoolchildren in Kuwait. Med Princ Pract. 2011; 20: 350-355.

4. BusatoI P, Garbin RR, Santos CN, Paranhos LR, Rigo L. Influence of maternal anxiety on child anxiety during dental care: cross-sectional study. Med J. 2017; 135(2): 116-122.

5. Armfield JM, Heaton LJ. Management of fear and anxiety in the dental clinic: a review. Aust Dent J. 2013; 58: 390-407.

6. Tellez M, Potter CM, Kinner DG, Jensen D, Waldron E, Heimberg RG, et al. Computerized tool to manage dental anxiety: a randomized clinical trial. J Dent Res. 2015; 94(9 suppl.): 174S-180S.

7. Kaczmarek U. Metody behawioralne kształtujące zachowanie dziecka $\mathrm{w}$ gabinecie stomatologicznym na podstawie piśmiennictwa. Czas Stomatol., 2009; 62(6): 456-466.

8. Facco E, Zanette G. The odyssey of dental anxiety: from prehistory to the present. A narrative review. Front Psychol. 2017; 8: 1155.

9. Vishwakarma AP, Bondarde PA, Patil SB, Dodamani AS, Vishwakarma PY, Mujawar SA. Effectiveness of two different behavioral modification techniques among 5-7-year-old children: A randomized controlled trial. J Indian Soc Pedod Prev Dent. 2017; 35: 143-149.

10. Ghadimil S, Estaki Z, Rahbar P, Shamshiri AR. Effect of visual distraction on children's anxiety during dental treatment: a crossover randomized clinical trial. Eur Arch Paediatr Dent. 2018 Jun 12. doi: 10.1007/s40368-018-0352-x. [Epub ahead of print]

11. Farhat-McHayleh N, Harfouche A, Souaid P. Techniques for managing behaviour in pediatric dentistry: comparative study of live modelling and tell-show-do based on children's heart rates during treatment. J Can Dent Assoc. 2009; 5(4): 283.

12. Heaton LJ, Leroux BG, Ruff PA, Coldwe SE. Computerized dental injection fear treatment: a randomized clinical trial. J Dent Res. 2013; 92(7 suppl.): $37 \mathrm{~S}-42 \mathrm{~S}$. 
13. Afshar H, Nakhjavani YB, Mahmoudi-Gharaei J, Mehrsa Paryab M, Zadhoosh S. The effect of parental presence on the 5 year-old children's anxiety and cooperative behavior in the first and second dental visit. Iranian J Pediatr, 2011; 21(2): 193-200.

14.Pani SC, AlAnazi GS, AlBaragash A, AlMosaihel M. Objective assessment of the influence of the parental presence on the fear and behavior of anxious children during their first restorative dental visit. J Int Soc Prev Community Dent. 2016; 6(Suppl 2): 148-152.

15. Singh H, Meshram GK, Warhadpande MM, Pooja Kapoor P. Effect of 'perceived control' in management of anxious patients undergoing endodontic therapy by use of an electronic communication system. J Conserv Dent. 2012; 15(1): 51-55.

16. Kazancioglu HO, Dahhan AS, Acar AH. How could multimedia information about dental implant surgery effects patients' anxiety level? Med Oral Patol Oral Cir Bucal. 2017; 22(1): 102-107.

17. Kazancioglu HO, Tek M, Ezirganli E, Demirtas N. Does watching a video on third molar surgery increase patients' anxiety level? Oral Med Oral Pathol Oral Radiol. 2015; 119(3): 272-277.

18. Costa Rank RCI, Sampaio Rank M, Rezende Vilela JE, Ogawa WN, Nahás Pires Correa MS. Dental anxiety and behavior in young children undergoing different distraction techniques. Pesq Bras Odontoped Clin Integr. 2017; 17(1): 1-11.

19. Hasselblad T, Reuterskiöld L, Kaldo V, Dahllöf G. Internet-based cognitive behavioral therapy for children and adolescents with dental anxiety: open trial. J Med Internet Res. 2018; 20: 1-12.

20. Shahnavaz S, Rutley S, Larsson K, Dahllöf G. Children and parents' experiences of cognitive behavioral therapy for dental anxiety - a qualitative study. Int J Paediatr Dent. 2015; 25(5): 317-326.

21. Matsuoka H, Itsuo Chiba I, Sakano Y, Toyofuku A, Abiko Y. Cognitive behavioral therapy for psychosomatic problems in dental settings. Biopsychosoc Med. 2017; 6: 1-7.

22. Haukebøa K, Skaretb E, Raadalb M, Bergb E, Sundbergd S, Kvale G. Onevs. five-session treatment of dental phobia: a randomized controlled study. J Behav Ther Exp Psychiatry. 2008; 39: 381-390.

23. Wide Boman U, Carlsson V, Westin M, Hakeberg M. Psychological treatment of dental anxiety among adults: a systematic review. Eur J Oral Sci. 2013; 121: 225-234.

24. Forbes MDL, Boyle CA, Newton T. Acceptability of behaviour therapy for dental phobia. Community Dent Oral Epidemiol. 2012; 40: 1-7.

25. Shahnavaz S, Hedman E, Grindefjord M, Reuterskiöld L, Dahllöf G. Cognitive behavioral therapy for children with dental anxiety: a randomized controlled trial. JDR Clin Trans Res. 2016; 10(1): 234-243.

26. Porritt J, Rodd H, Morgan A, Williams C, Gupta E, Kirby J, et al. Development and testing of a cognitive behavioral therapy resource for children's dental anxiety. JDR Clin Trans Res. 2017; 2(1): 23-37.

27. Dumitrache MA, Neacsub V, Sfeatcuc IR. Efficiency of cognitive technique in reducing dental anxiety. Procedia Soc Behav Sci. 2014; 149: 302-306.

28. Kritsidima M, Newton T, Asimakopoulou K. The effects of lavender scent on dental patient anxiety levels: a cluster randomized-controlled trial. Community Dent Oral Epidemiol. 2010; 38(1): 83-87.
29. Garrocho-Rangel A, Ibarra-Gutiérrez E, Rosales-Bérber M, EsquivelHernández R, Esparza-Villalpando V, Pozos-Guillén A. A video eyeglasses/earphones system as distracting method during dental treatment in children: a crossover randomised and controlled clinical trial. Eur J Paediatr Dent. 2018; 19(1): 74-79.

30. Aminabadi NA, Erfanparast L, Sohrabi A, Ghertasi Oskouei S, Naghili A. The impact of virtual reality distraction on pain and anxiety during dental treatment in 4-6 year-old children: a randomized controlled clinical trial. J Clin Diagn Res. 2012; 6(4): 117-127.

31. Diana Ram D, Shapira J, Holan G, Magor F, Cohen S, Audiovisual video eyeglass distraction during dental treatment in children. Quintessence Int 2010; 41: 673-679.

32. Panda A. Effect of virtual reality distraction on pain perception during dental treatment in children. Int J Oral Care Res. 2017; 5(3): 1-4.

33. Fakhruddin KS, Gorduysus MO, El Batawi H. Effectiveness of behavioral modification techniques with visual distraction using intrasulcular local anesthesia in hearing disabled children during pulp therapy. Eur J Dent. 2016; 10(4): 551-555.

34. Thoma MV, Zemp M, Kreienbühl L, Hofer D, Schmidlin PR, Attin T, et al. Effects of music listening on pre-treatment anxiety and stress levels in a dental hygiene recall population. Int J Behav Med. 2015; 22: 498-505.

35. Mehr K, Wyganowska-Świątkowska M, Kowalkowska I, KurhańskaFlisykowska A, Piotrowski P. Music therapy in different dental specialities. Przeg. Lek. 2012; 69(10): 1049-1052.

36. Navit S, Johri N, Khan SA, Singh RK, Chadha D, Navit P. Effectiveness and comparison of various audio distraction aids in management of anxious dental paediatric patients. J Clin Diagn Res. 2015; 9(12): 5-9.

37. Klassen JA, Liang Y. Tjosvold L, Klassen TP, Hartling L. Music for pain and anxiety in children undergoing medical procedures: a systematic review of randomized controlled trials. Ambulatory Pediatrics. 2008; 8: 117-128.

38. Kim YK, Kim SM, Myoung H. Musical intervention reduces patient's anxiety in surgical extraction of an impacted mandibular third molar. J Oral Maxillofac Surg. 2011; 69: 1036-1045.

39. Lahmann C, Schoen R, Peter Henningsen P, Ronel J, Muehlbacher M, Loew T, et al. Brief relaxation versus music distraction in the treatment of dental anxiety: a randomized controlled clinical trial. J Am Dent Assoc. 2008; 139(3): 317-324.

40. Holden A. The art of suggestion: the use of hypnosis in dentistry. Br Dent J. 2012; 212(11): 549-551.

41. Oboda M, Pająk J. Zastosowanie hipnozy w stomatologii. e-Dentico. 2014; 4(38): 128-132.

42. Rauch Ch, Panek H. Hypnosis in daily dental practice. Dent. Med. Probl. 2008; 45(3): 301-306.

43. Meyerson J, Uziel N. Application of hypno-dissociative strategies during dental treatment of patients with severe dental phobia. Int J Clin Exp Hypn. 2014; 62(2): 179-187.

44. Panek H, Makacewicz S, Barzyk M. Evaluation of patients' acceptance of hypnosis prior to selected dental procedures. Czas Stomatol. 2009; 62(6): 493-501. 